\title{
Naloxone for opioid toxicity and overdose in the community
}

\author{
Marianne Jauncey (C) \\ Medical director? \\ Adjunct senior lecturer ${ }^{2}$ \\ Clinical senior lecturer ${ }^{3}$ \\ Suzanne Nielsen (D) \\ Associate professor and \\ Deputy director ${ }^{4}$ \\ Adjunct associate \\ professor $^{2}$ \\ ${ }^{1}$ Uniting Medically \\ Supervised Injecting Centre, \\ Sydney \\ 2 National Drug and Alcohol \\ Research Centre, UNSW \\ Sydney \\ ${ }^{3}$ Sydney Medical School, \\ University of Sydney \\ ${ }^{4}$ Monash Addiction \\ Research Centre, Monash \\ University, Melbourne
}

\section{Keywords}

drug dependence, drug

overdose, naloxone, opioids

Aust Prescr 2021;44:38-9

https://doi.org/10.18773/

austprescr.2021.006

\section{Opioid-related harms, especially accidental} overdose deaths, have been increasing for over a decade. While there have been large increases in heroin deaths in the past five years, ${ }^{1}$ approximately two-thirds of the more than 1000 opioid-related deaths per year are now from prescription opioids. Addressing inappropriate opioid prescribing is one way to reduce this death toll, however naloxone also has a role to play. Patients taking prescription opioids do not perceive themselves as being at risk of overdose, so there is a need for a broader conversation about opioid safety and toxicity. This conversation can involve the patient's family and friends. Naloxone is commonly associated with managing heroin overdoses but it should be considered for all opioid toxicity.

Naloxone acts as an opioid reversal drug by competitive antagonism at opioid receptors. It is safe to use and has no abuse liability. However, awareness of naloxone varies greatly by jurisdiction and patient population. ${ }^{2,3}$ The Pharmaceutical Benefits Scheme (PBS) began subsidising naloxone in 2013. The drug was rescheduled in 2016 and is now available over-the-counter across Australia. However, when sold without a prescription there is no PBS subsidy, so naloxone can cost $\$ 50$ or more. While both the rescheduling and the PBS subsidy were positive steps, unfortunately the actual amount of naloxone in the community has not increased as a result. Most naloxone was still being supplied as a PBS Prescriber Bag item rather than being obtained over-the-counter. ${ }^{4}$

In early 2019, the Australian Government therefore funded a pilot program in New South Wales, South Australia and Western Australia to provide naloxone free of charge through participating pharmacies and other services to people at risk of opioid overdose, and their carers and friends. ${ }^{5}$ The pilot has been extended until June 2021. No data from this two-year pilot are available yet, but removing cost barriers could increase community access to naloxone. Importantly, naloxone should not only be considered for people who inject drugs. With the ever-increasing number of deaths involving prescription opioids, patients prescribed opioids for pain, particularly those on higher doses or with other risk factors for toxicity, could also benefit from improved community access to naloxone.
There are now two naloxone products available in Australia that are packaged to be suitable for administration by the public. The intramuscular formulation has been available for several years, but the skills needed to inject it can be a barrier to its use. In November 2019 an intranasal spray was listed on the PBS. ${ }^{6}$ Administration is straightforward - a single metered dose is sprayed into one nostril. This formulation simplifies education on how to use naloxone and removes barriers for those who may not feel comfortable giving injections. A single intranasal dose (1.8 $\mathrm{mg}$ naloxone) is considered equivalent to the recommended initial intramuscular dose $(0.4 \mathrm{mg})$ in the community setting. For either formulation, doses can be repeated every $2-3$ minutes until there is a response or an ambulance arrives. If using the intranasal spray, repeated doses should be given into alternate nostrils.

Anyone who prescribes opioids for the treatment of pain or opioid dependence has an important role to play in discussing how to minimise harm. Ideally this discussion around opioid safety should include reviewing other drugs, especially central nervous system depressants, and a consideration of prescribing naloxone. Health professionals should be routinely and automatically discussing signs of opioid toxicity and the availability of naloxone with two main groups. These are firstly, all people receiving long-term opioids. Although those with opioid dependence who inject drugs are often knowledgeable about the signs to look out for, people prescribed opioids for pain generally have little knowledge about overdose. ${ }^{3}$ Informing them can be both empowering and potentially lifesaving. ${ }^{7}$ The second group that health professionals should be educating includes families, carers or significant others to identify the signs and symptoms of overdose. Having naloxone available can be reassuring for them when a patient is trying to reduce the use of prescribed opioids. They need to know when and how to administer naloxone and to always call an ambulance. Health professionals should advocate for wide availability of naloxone in high-risk settings, such as community healthcare centres, homeless hostels and drug treatment programs including residential rehabilitation. Ensuring people have naloxone on hand in case of an emergency becomes even more important for anyone working in rural and regional areas. The longer wait times for an ambulance place even more emphasis on early intervention. Opioids 


\section{<ustralian Prescriber}

VOLUME 44 : NUMBER 2 : APRIL 2021

kill and injure through respiratory depression so every minute of anoxia counts.

Routine practice needs to change. Opioid-related deaths are increasing yet many are preventable. Proactive conversations about opioid safety should be part of routine care. Regularly discussing naloxone can help increase awareness of this lifesaving and safe medicine. Ensuring access can empower both the people at risk of harm and those who may witness and be able to respond to an overdose. $<$
Conflicts of interest: Suzanne Nielsen has received unrelated research funding from Indivior and Seqirus (to study opioid dependence treatment and opioidrelated harms). Suzanne Nielsen and Marianne Jauncey attended an advisory meeting on intranasal naloxone convened more than three years ago by Mundipharma (no fee was taken).

\section{REFERENCES}

1. Australian Institute of Health and Welfare. Opioid harm in Australia and comparisons between Australia and Canada. Cat. no. HSE 210. Canberra: AlHW; 2018.

https://www.aihw.gov.au/reports/illicit-use-of-drugs/ opioid-harm-in-australia/contents/table-of-contents [cited 2021 Mar 1]

2. Dietze PM, Stare M, Cogger S, Nambiar D, Olsen A, Burns L, et al. Knowledge of naloxone and take-home naloxone programs among a sample of people who inject drugs in Australia: variations across capital cities. Drug Alcohol Rev 2018;37:457-63. https://doi.org/10.1111/dar.12644

3. Nielsen S, Peacock A, Lintzeris N, Bruno R, Larance B, Degenhardt L. Knowledge of opioid overdose and attitudes to supply of take-home naloxone among people with chronic noncancer pain prescribed opioids. Pain Med 2018;19:533-40. https://doi.org/10.1093/pm/pnx021

4. Tse WC, Sanfilippo P, Lam T, Dietze P, Nielsen S. Community pharmacy naloxone supply, before and after rescheduling as an over-the-counter drug: sales and prescriptions data, 2014-2018. Med J Aus 2020;212:314-20. https://doi.org/ $10.5694 / \mathrm{mja} 2.50524$
5. Minister for Health 2019 \$268 million to continue the battle against alcohol and drug misuse [Media Release] 2019 Feb 27. https://www.health.gov.au/ministers/the-hongreg-hunt-mp/media/268-million-to-continue-the-battleagainst-alcohol-and-drug-misuse [cited 2021 Mar 1]

6. Naloxone nasal spray (Nyxoid) for opioid overdose. RADAR 2020 Jan 15. https://www.nps.org.au/radar/articles/ naloxone-nasal-spray-nyxoid-for-opioid-overdose [cited 2021 Mar 1]

7. Coffin PO, Behar E, Rowe C, Santos G-M, Coffa D, Bald M, et al. Nonrandomized intervention study of naloxone coprescription for primary care patients receiving long-term opioid therapy for pain. Ann Intern Med 2016;165:245-52 https://doi.org/10.7326/M15-2771 